\title{
Gestão ambiental: investigação sobre a Área de Proteção Ambiental da Região do Maracanã (MA)
}

\section{Environmental management: Research on Environmental Protection Area of the Maracanã Region (MA, Brazil)}

Rosélis de Jesus Barbosa Câmara, Rozuila Neves Lima

\begin{abstract}
RESUMO
O presente trabalho trata sobre a temática sociedade/natureza e suas interações a partir de uma reflexão sobre a necessidade de se pensar mecanismos que aliem questões como desenvolvimento e proteção dos recursos naturais. Dentro dessa proposta, aborda sobre gestão ambiental em áreas naturais protegidas e a prática da atividade turística. Investiga a unidade de conservação Área de Proteção Ambiental (APA) da Região do Maracanã, o seu processo de gestão e os instrumentos adotados nesse processo. A APA está localizada a $18 \mathrm{~km}$ do centro de São Luís/MA e foi regulamentada em 1991 e além de seu valor ambiental, é detentora de representativo valor cultural e histórico. Sua gestão é de responsabilidade da Secretaria de Estado de Meio Ambiente e Recursos Naturais do Maranhão (SEMA). A investigação foi constituída de duas etapas delineadas em pesquisa bibliográfica e pesquisa de campo. Durante a pesquisa de campo foram realizadas visitas técnicas a área de estudo para averiguar a situação da APA quanto a sua gestão. Também foram realizadas entrevistas com agente ambiental e com representante da Secretaria de Estado de Meio Ambiente e Recursos Naturais do Maranhão. Como resultado, a pesquisa apontou que a situação atual da Área de Proteção Ambiental da Região do Maracanã é de risco e por isso requer a implantação imediata de uma gestão ambiental que seja capaz de garantir a manutenção da sua diversidade biológica, disciplinar seu processo de ocupação e assegurar a sustentabilidade dos recursos naturais e culturais que motivaram a sua criação.
\end{abstract}

KEYWORDS: Gestão Ambiental; Unidade de Conservação; Área de Proteção Ambiental; Região do Maracanã. 


\begin{abstract}
This research attend with the theme society / nature and their interactions as from a reflection about necessity to consider mechanisms that connecting issues as development and protection of natural resources. Inside this proposal, approach about environmental management in protected natural areas and the practice of tourism activities. Investigates the protected area Environmental Protection Area (APA) of the Maracanã Region, His management process and the tools adopted in this process. This place is 18 miles from the center of São Luís (MA, Brazil), was regulated in 1991, and besides its environmental value, is owner of representative cultural and historical value. Its management is from responsibility of the State Secretariat of Environment and Natural Resources of Maranhão. The investigation was done in two outlined steps in bibliographic research and field research. During the field research were made technical visits to the study area to investigate the situation of APA about this management. Was also made interviews with environmental agent and representative of the State Department of Environment and Natural Resources of Maranhão. As a result, the research indicated that the present situation of the Environmental Protection Area of the Maracanã Region is risk and because that requires the immediate deployment of an environmental management wich is capable of guarantee the maintenance of biological diversity, to discipline his occupation process and secure the sustainability of natural and cultural resources that motivated its creation.
\end{abstract}

KEYWORDS: Environmental Management; Protect Area; Maracanã.

\title{
Introdução
}

O desenvolvimento do conhecimento científico e suas aplicações tecnológicas possibilitam, em escala crescente, muitas inovações em nossa sociedade. Dispomos hoje de sistemas de comunicação com alto grau de eficiência que dinamizam os diversos setores das organizações e da sociedade como um todo. No campo científico, grandes descobertas têm sido realizadas em todas as áreas do conhecimento garantindo cada vez mais qualidade de vida à humanidade. No setor de serviços, a informatização possibilita oferecer maior conforto, tranquilidade e agilidade a seus clientes. Contudo, para subsidiar todas essas inovações, os recursos naturais são explorados em grandes quantidades e, consequentemente, ocasionam profundas alterações no equilíbrio natural dos ecossistemas. Esse cenário tem levado ao aumento das discussões acerca da gestão dos recursos ambientais. São debates preocupados com a natureza e com os seus recursos, regulados pela obrigação de se pensar mecanismos que, de forma mais racional, aliem questões como desenvolvimento e proteção dos recursos naturais. Atualmente esses debates permeiam a nossa sociedade nas mais distintas esferas, estão presentes no cotidiano do simples cidadão e nas escalas superiores das organizações, dos agentes econômicos e sociais.

Os resultados dessas reflexões têm decorrido em mudanças de postura da sociedade e das organizações em relação aos recursos naturais e contribuído para a elaboração de uma legislação voltada à proteção ambiental. No Brasil, foram instituídas importantes leis ambientais que colaboram para a manutenção do patrimônio ambiental aqui existente. Dentre essas leis, destacamos neste estudo, a Lei n 9985, de 18 de julho 
de 2000, que institui o Sistema Nacional de Unidades de Conservação da Natureza (SNUC), cujo propósito é estabelecer critérios para a criação, implantação e gestão das unidades de conservação, áreas detentoras de características naturais relevantes cujo papel é importante na manutenção da diversidade biológica e de ecossistemas no país.

Atualmente, existem centenas de Unidades de Conservação (UC) no Brasil, divididas em dois grandes grupos, os quais se subdividem em diversas categorias. O uso e manejo de seus recursos naturais são determinados de acordo com a categoria a que pertencem. Essas áreas são criadas pelo poder público, nas suas distintas esferas, e possuem regime especial de administração para garantir a integridade do seu patrimônio para as gerações atuais e futuras.

A forma de gestão dessas unidades de conservação é fundamental para 0 alcance dos objetivos para os quais foram criadas. Assim, vários instrumentos de gestão ambiental podem ser adotados no sentido de auxiliar na conservação e preservação dessas áreas naturais protegidas. Nesse contexto, o objetivo deste trabalho é investigar sobre a unidade de conservação da Área de Proteção Ambiental (APA) da Região do Maracanã, averiguar o seu processo de gestão, bem como os instrumentos adotados nesse processo. A APA pertence ao grupo de unidades de conservação de uso sustentável e se encontra a $18 \mathrm{~km}$ do centro de São Luís/MA, com área total de 1.831ha. Ressalva-se que esta área é uma categoria de UC que permite a ocupação humana de forma compatível com o uso sustentável dos seus recursos naturais.

\section{Fundamentação teórica}

\section{Entendendo Gestão Ambiental}

As primeiras discussões voltadas para a defesa da natureza têm registro na década de 1960, por meio da publicação do livro "Primavera Silenciosa" de autoria de Rachel Carson e das discussões realizadas pelo Clube de Roma. Em 1972 ocorreu a publicação de um relatório tido como pioneiro na abordagem da relação entre desenvolvimento e exploração dos recursos naturais, sob o título "Limites do Crescimento". Desde então vários fóruns foram criados para discutir e propor alternativas que visam o equilíbrio do uso dos recursos naturais pela sociedade. No Brasil, essas proposições ganharam espaço a partir da década de 1980, estimuladas pelas numerosas discussões que aconteciam ao redor do mundo. Assim, em 1981 foi estabelecida uma base legal mais sólida voltada para o meio ambiente. Foram as diretrizes para a Política Nacional de Meio Ambiente e, em 1988, houve a promulgação da Constituição Federal, primeira no Brasil a consagrar um capítulo exclusivo ao tema meio ambiente. A implementação dessas leis criou um aparato legal que contribuiu para que a temática se firmasse na pauta de discussão e passasse a ser estudada sob diversas perspectivas, inclusive a da gestão ambiental.

No que se refere à gestão ambiental, pode-se dizer que se trata de uma área do conhecimento bastante nova, que emergiu após a propagação da crise ambiental, na década de 1970. Por esse motivo, muito pouco ainda se tem como referencial teórico sobre a temática. 
A gestão ambiental corresponde a um ramo do sistema administrativo de uma organização que se preocupa com a relação entre as suas atividades e os recursos ambientais, mas ganha vários contornos dependendo do foco que lhe é dado. Assim, Barbieri (2007) observa que a gestão ambiental pode ser interpretada como as diretrizes, as atividades administrativas e operacionais, tais como planejamento, direção, controle, alocação de recursos e outras atividades que são realizadas com o objetivo de obter efeitos positivos sobre o meio ambiente. Em consonância com esse pensamento, Leff (2001) menciona que a gestão ambiental diz respeito à forma de administrar o uso dos recursos naturais, objetivando a minimização dos impactos gerados pela ação antrópica. Logo, a gestão ambiental tem a função de planejar, coordenar e propor ações visando o equilíbrio entre os aspectos naturais associados às questões econômicas, sociais, políticas, dentre outras.

Conforme Theodoro et al. (2005, p. 10), dentre as principais funções da gestão ambiental estão o planejamento, que determina previamente as ações efetivas da gestão; a organização, que trata das relações formais entre os atores envolvidos, visando a consecução dos objetivos estabelecidos; a direção, que atua no comportamento dos envolvidos no processo e o controle que acompanha os resultados obtidos e compara com os indicadores previamente estabelecidos.

Quando se trata de áreas naturais protegidas, a gestão ambiental deve ser compreendida como um conjunto de ações desenvolvidas por diversos atores (sociedade civil, poder público, iniciativa privada, dentre outros) direcionadas para o uso sustentável dos recursos naturais. Com isso (BRITO, 2000), observa que o termo gestão significa o conjunto de diretrizes e ações adotadas visando garantir, no caso das unidades de conservação, sua criação, implantação, proteção e manejo, com a finalidade de cumprir os objetivos previstos nas mais diferentes categorias de manejo. Brito (2000, p. 134). Logo, a gestão ambiental constitui-se em uma ferramenta capaz de minimizar os impactos negativos evidenciados dentro dessas áreas e no seu entorno, buscando de forma permanente, níveis de eficiência para que os objetivos da área natural protegida sejam alcançados.

Dessa forma, os procedimentos adotados na gestão ambiental de uma unidade de conservação devem garantir um meio ambiente ecologicamente equilibrado e buscar estabelecer uma relação harmônica entre homem e recursos naturais, corroborando, portanto para a conservação da biodiversidade e para o uso sustentável dos recursos naturais nessas áreas.

\section{Contextualizando Unidades de Conservação}

À medida que o modelo de desenvolvimento vigente apresenta seus efeitos negativos mais graves, crescem o interesse e o envolvimento dos vários segmentos da sociedade com as questões ambientais e uma preocupação maior com a qualidade de vida humana. Houve 0 reconhecimento de que a salvaguarda do meio ambiente é necessária sob vários aspectos, fato que influenciou, de maneira decisiva, no aumento da criação das unidades de conservação no Brasil e no mundo, pois estas além de representarem espaços essenciais para a conservação ou 
preservação de recursos naturais e contribuírem com a qualidade de vida da sociedade, - destacam-se, também, pelos seus valores estéticos, já que geralmente são detentoras de relevantes belezas naturais e, para muitos, representam pedaços do paraíso na terra. A criação destas leva em consideração, dentre outros aspectos, a relevância de suas características naturais e a sua importância para a proteção de espécies de fauna e de flora ameaçadas de extinção.

Essas áreas naturais são protegidas legalmente $\mathrm{e}$, conforme a categoria em que se inserem, permitem acesso à visitação fazendo com que as pessoas tenham a oportunidade de perceber a relação homem-natureza e a importância dos recursos naturais para a nossa sobrevivência. Assim, a criação de unidades de conservação representa, na atualidade, uma das principais formas de intervenção encontrada pelos governos - municipal, estadual e federal - na tentativa de reduzir o processo de degradação ambiental e de preservar sistemas naturais.

Diante desse cenário, houve a necessidade de se estabelecer critérios e normas para a gestão dessas áreas. No Brasil, foi sancionada a Lei 9.985/2000, instituindo o Sistema Nacional de Unidade de Conservação (SNUC), pelo qual unidade de conservação é assim definida:

Superfície de terra ou mar consagrada à proteção e manutenção da diversidade biológica, assim como dos recursos naturais e dos recursos culturais associados, e manejada através de meios jurídicos e outros meios eficazes [lei 9985, art 2ํㅜ parágrafo I] (COSTA, 2002, p.137).

Agrupadas a partir de suas finalidades e características naturais, as unidades de conservação possuem limites físicos determinados e podem ser administradas pelo poder público ou pela iniciativa privada. No SNUC estão estabelecidas as diretrizes e normas que devem conduzir as ações desenvolvidas nessas áreas. Além das diretrizes, estão contemplados também os principais objetivos do SNUC, dentre os quais elencamos:

I - contribuir para a manutenção da diversidade biológica e dos recursos genéticos no território nacional e nas águas jurisdicionais;

II - proteger as espécies ameaçadas de extinção no âmbito regional e nacional;

III - contribuir para a preservação e a restauração da diversidade de ecossistemas naturais;

IV - promover o desenvolvimento sustentável a partir dos recursos naturais;

$[\ldots]$

$\mathrm{VI}$ - proteger paisagens naturais e pouco alteradas de notável beleza cênica [lei 9985/2000] (COSTA, 2002, p. 140). 
A Lei 9.985/2000 estabeleceu, a partir das características específicas das áreas naturais protegidas, dois grandes grupos de unidades de conservação:

a) Unidades de Proteção Integral, em que se inserem as áreas criadas com o objetivo de preservar a natureza e manter os ecossistemas livres de alterações causadas pela ação humana. Nessas unidades, só é permitido o uso indireto dos recursos naturais, exceto nos casos previstos em lei;

b) Unidades de Uso Sustentável, estando inseridas nesse grupo as unidades de conservação que têm como objetivo básico a utilização da natureza de maneira compatível com a sustentabilidade, sem colocar em risco sua dinâmica natural, a fim de garantir perenidade de parcela dos recursos naturais.

c)

Esses dois grupos abrigam distintas categorias de unidades de conservação, conforme quadro a seguir:

Quadro 1: Categorias de Unidades de Conservação.

Table 1: Categories of Protect Areas.

\begin{tabular}{|c|c|}
\hline Unidades de Proteção Integral & Unidades de Uso Sustentável \\
\hline Estação Ecológica & Área de Proteção Ambiental \\
\hline Reserva Biológica & Área de Relevante Interesse Ecológico \\
\hline Parque Nacional & Floresta Nacional \\
\hline Monumento Natural & Reserva Extrativista \\
\hline Refúgio de Vida Silvestre & Reserva de Fauna \\
\hline & Reserva de Desenvolvimento Sustentável \\
\hline & Reserva Particular do Patrimônio Natural \\
\hline
\end{tabular}

Fonte: Brasil (2000a).

Source: Brasil (2000a)

Em meio à diversidade de categorias de UC, optamos neste trabalho, por lançar um olhar sobre unidades de conservação de uso sustentável. Contudo, antes de apresentarmos suas características, é oportuno lembrar que, conforme a Convenção da Biodiversidade, uso sustentável significa:

a utilização de componentes da diversidade biológica de modo e em ritmo tais que não levem, no longo prazo, à diminuição da diversidade biológica, mantendo assim seu potencial para atender as necessidades e aspirações das gerações presentes e futuras (BRASIL, 2000b, p. 9).

Nesse sentido, unidades de conservação de uso sustentável, têm por objetivo básico "compatibilizar a conservação da natureza com o uso sustentável de parcela dos seus recursos naturais" (BRASIL, 2000a). Nesse grupo de UCs se encontram as Áreas de Proteção Ambiental, as quais, conforme o Sistema Nacional de Unidade de Conservação, são assim definidas: 


\begin{abstract}
área em geral extensa, com um certo grau de ocupação humana, dotada de atributos abióticos, bióticos, estéticos ou culturais especialmente importantes para a qualidade de vida e o bem-estar das populações humanas, e tem como objetivos básicos proteger a diversidade biológica, disciplinar o processo de ocupação e assegurar a sustentabilidade do uso dos recursos naturais (art. 15) (BRASIL, 2000a).
\end{abstract}

A conservação da biodiversidade e o uso sustentável dos recursos nessas áreas protegidas são fundamentais para que estas alcancem os objetivos que motivaram a sua criação. Seu espaço territorial pode ser constituído por terras públicas e privadas. Dessa forma, para a realização de pesquisas científicas e de visitação pública, há a necessidade de o órgão gestor da unidade e o proprietário estabelecerem as condições, respectivamente. Sendo que o proprietário, para estabelecer as normas, deverá cumprir as determinações legais para o caso.

De acordo com o Decreto no 4.340 de 22 de agosto de 2002, no Artigo $2^{\circ}$, o ato de criação de uma unidade de conservação deve indicar sua denominação, a categoria de manejo, os objetivos, os limites, a área da unidade e o órgão responsável por sua administração. O referido decreto também garante a participação da sociedade no processo de criação, implementação e gestão das UCs, visando a melhor adequação da gestão ambiental nesses espaços.

\title{
Instrumentos de Gestão em Unidade de Conservação
}

As diversas políticas ambientais formuladas nos últimos anos visam garantir a salvaguarda do patrimônio natural. Com essas políticas emergiram instrumentos legais direcionados à gestão desse patrimônio. Conforme observam (BITAR; ORTEGA, 1998), instrumentos de gestão ambiental correspondem: "à sistematização de procedimentos técnicos e administrativos para assegurar a melhoria e o aprimoramento contínuo do desempenho ambiental de um empreendimento ou de uma área protegida".

Nessa direção, o SNUC apresenta vários instrumentos de gestão ambiental para uma unidade de conservação, visando à articulação das ações dos diferentes agentes sociais a fim de garantir um meio ambiente ecologicamente equilibrado e estabelecer uma relação harmônica entre homem e recursos naturais. Assim, baseados no SNUC, elegemos os instrumentos de gestão ambiental - Plano de manejo e Conselho Gestor para realizarmos uma investigação na Área de Proteção Ambiental da Região do Maracanã. Além desses, selecionamos também a Visitação Pública e a Educação Ambiental que apesar de não figurarem como instrumentos de gestão do SNUC, constituem-se ferramentas importantes no processo de gestão de uma unidade de conservação. Buscamos verificar neste estudo quais desses instrumentos são utilizados na/pela administração da APA. Antes, porém, apresentamos algumas informações sobre cada um deles e a importância dos mesmos na gestão de uma área natural protegida. 


\title{
a) Plano de Manejo
}

O plano de manejo constitui um documento técnico essencial para 0 planejamento de uma unidade de conservação e, de acordo com o SNUC Lei 9.985/2000 - deve ser elaborado nos primeiros cinco anos de existência da unidade. Nele, estão estabelecidas as normas que devem determinar as formas de uso da área e o manejo dos recursos naturais, prevendo, inclusive, a criação de estruturas físicas que auxiliem no processo de gestão da área protegida. Consta, também, um diagnóstico da área, realizado a partir de suas características históricas, geográficas, ambientais, sociais e econômicas, além de várias outras informações.

Para a elaboração de um plano de manejo, um dos passos importantes é a inclusão dos atores sociais interessados. Assim, o Instituto Chico Mendes de Conservação da Biodiversidade (ICMBio, 2014,n.p) observa que:

\begin{abstract}
- Plano de Manejo deve ser elaborado sob um enfoque multidisciplinar, com características particulares diante de cada objeto específico de estudo. Ele deve refletir um processo lógico de diagnóstico e planejamento. Ao longo do processo devem ser analisadas informações de diferentes naturezas, tais como dados bióticos e abióticos, socioeconômicos, históricos e culturais de interesse sobre a Unidade de Conservação e como estes se relacionam.
\end{abstract}

\section{b) Conselho Gestor}

Conforme estabelece o SNUC, no art. 15, parágrafo 5으, a Área de Proteção Ambiental deverá possuir um conselho gestor, cuja presidência compete ao órgão que a administra. Deverão ainda compor o conselho representantes de órgãos públicos, da sociedade civil organizada e da população residente, além de organizações não governamentais que atuem na região em que a UC está inserida.

Uma das competências do conselho é assessorar a chefia da unidade de conservação na sua gestão. Sua formação ocorre geralmente antes da elaboração do Plano de Manejo, pois conforme SNUC, art. 18, este deverá acompanhar o processo de elaboração, aprovar e acompanhar sua execução e revisão. Deve, ainda, procurar harmonizar os interesses dos distintos setores sociais ligados à unidade, posicionar-se sobre as atividades que podem causar impactos negativos à unidade de conservação, além de propor procedimentos que visem compatibilizar, agregar e otimizar a relação com a população do entorno ou do interior da unidade (BRASIL, 2014a).

\section{c) Visitação Pública}

Conforme exposto anteriormente, as áreas naturais protegidas, na forma de unidades de conservação, geralmente possuem atributos naturais e paisagísticos relevantes que favorecem a visitação pública. Esta, por sua vez, constitui uma das principais atividades capazes de gerar recursos financeiros para uma unidade de conservação e por isso deve ser 
estimulada. Entretanto, é necessário compatibilizar essa atividade às características e aos interesses da UC, garantindo a integridade dos recursos naturais ali existentes e a manutenção dos valores culturais do lugar. Assim, de acordo com o Manual de Monitoramento e Gestão dos Impactos da Visitação em Unidades de Conservação (SÃO PAULO, 2010, p. 9) reconhece a importância da Visitação Pública nas unidades de conservação ao afirmar que: "a visitação de lazer, recreativa, contemplativa, ou educativa, quando bem manejada, traz inúmeros benefícios à UC, através da promoção de sua proteção e conservação; benefícios sociais, através da educação ambiental e potencialidade de desenvolvimento regional".

A Lei 9.985/2000 determina as possibilidades de visitação de acordo com a categoria da área. No caso das Áreas de Proteção Ambiental, a visitação pública deve ser determinada pelo seu Conselho Gestor. Nas propriedades particulares, a responsabilidade de estabelecer as condições de visitação pública é do proprietário, ressalvadas as restrições legais.

\section{d) Educação Ambiental}

A Educação Ambiental é uma ferramenta fundamental quando o assunto é sustentabilidade, pois conforme a Lei o 9.795 de 27 de abril de 1999 - que institui a Política Nacional de Educação Ambiental -, um dos seus objetivos primeiros é atuar na preservação do equilíbrio do meio ambiente, incentivando a participação individual e coletiva nesse processo, pois a defesa da qualidade ambiental é entendida como valor inseparável do exercício da cidadania. Essa ferramenta tem sido utilizada, de maneira crescente, nos sistemas de gestão ambiental das empresas. Por meio da inserção de práticas educacionais direcionadas à conservação da biodiversidade e dos ecossistemas, estas empresas têm contribuído com uma melhor qualidade de vida para a sociedade. Assim, a interação entre Educação Ambiental e Gestão Ambiental constitui-se aspecto fundamental para o equilíbrio de ecossistemas.

Cabe ressaltar nesse contexto que, conforme art. $1^{\circ}$ da Lei 9.795/99, Educação Ambiental deve ser entendida como:

os processos por meio dos quais o indivíduo e a coletividade constroem valores sociais, conhecimentos, habilidades, atitudes e competências voltadas para a conservação do meio ambiente, bem de uso comum do povo, essencial à sadia qualidade de vida e sua sustentabilidade (BRASIL, 1999).

Assim, a Educação Ambiental pode ser vista como uma prática socioeducativa capaz de sensibilizar a sociedade e os gestores públicos, sobre a importância de se conhecer e diminuir os problemas ambientais e, por meio desse instrumento é possível estabelecer uma aproximação entre gestores das unidades e comunidade do entorno, fomentando uma participação 
integrada na busca da preservação do patrimônio ambiental e cultural da área protegida.

\section{Caracterização da área de estudo}

A Área de Proteção Ambiental da Região do Maracanã é uma Unidade de Conservação de uso sustentável que tem como finalidade conservar a diversidade de recursos biológicos que ali se encontram. Regulamentada por meio do Decreto Estadual 12.103/91 é detentora de uma área de 1831 hectares. Localizada no bairro do Maracanã (Figura 1), zona rural do município de São Luís (MA), essa APA está inserida no bioma Amazônia, e sua paisagem é constituída por uma vegetação local representada por espécies de babaçu, juçara, buriti, cupuaçu e bacuri entremeada por igarapés de água doce que ajudam a compor sua imagem turística. De acordo com a Lei 9985/2000 (BRASIL, 2000a) essa UC é detentora de um representativo valor cultural, histórico e paisagístico, muitas vezes utilizado para fins recreativos. É rica em recursos hídricos, mas que estão ameaçados pelas atividades com potencial de degradação realizadas no Distrito Industrial da Ilha de São Luís, cujos limites fazem fronteiras a leste, a oeste e ao sul com a APA (BRASIL, 2014b).

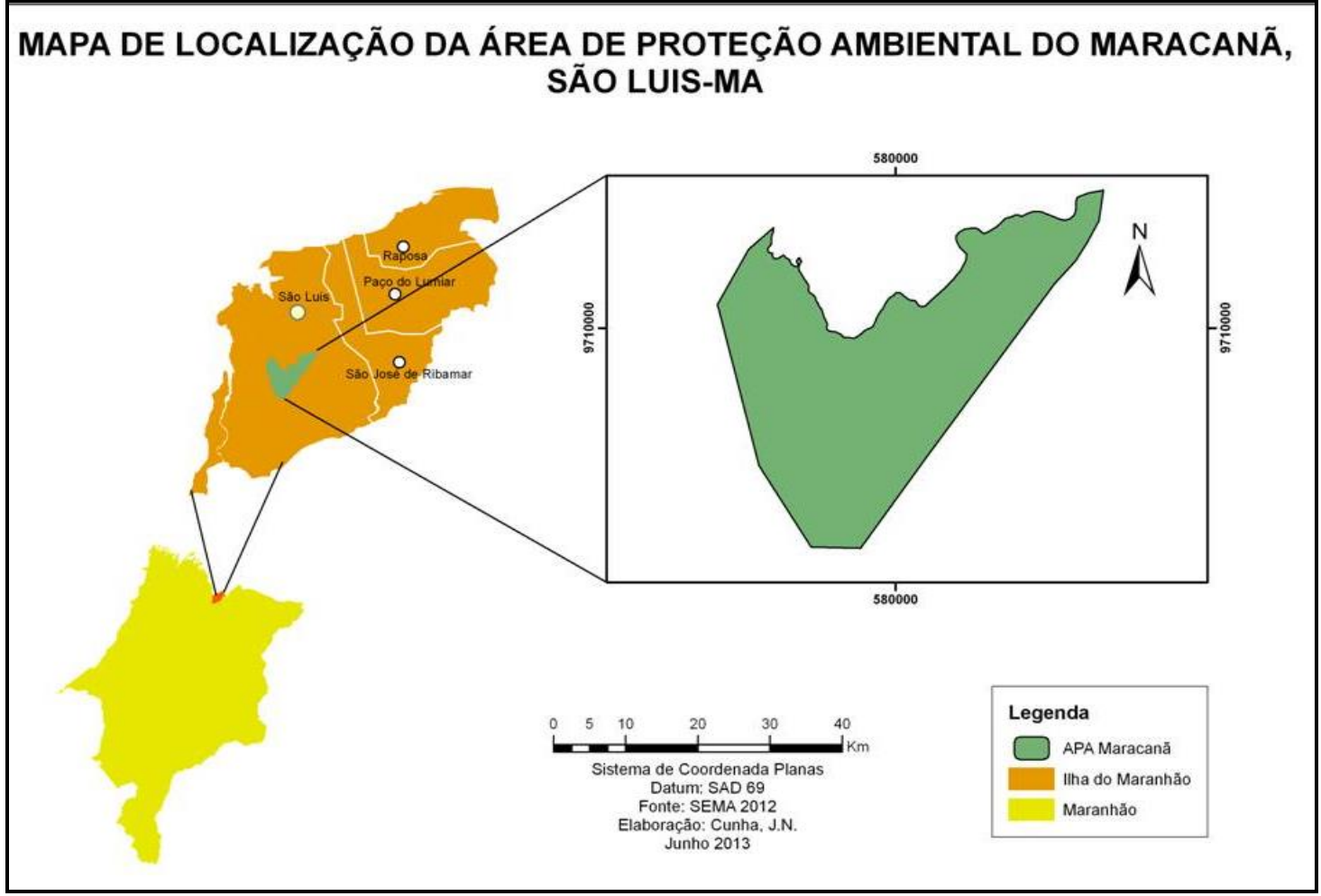

Figura 1: Mapa da Área de Proteção Ambiental da Região do Maracanã.

Fonte: SEMA (2012).

Figure 1: Map of the Environmental Protection Area of the Maracanã Region.

Source: SEMA (2012).

Devido à diversidade de recursos naturais e culturais existentes na APA do Maracanã, esta é utilizada pela população e por visitantes para a 
prática de atividades de lazer e turísticas. No interior da área existem trilhas ecológicas que permitem aos visitantes entrarem em contato com 0 patrimônio natural, histórico e cultural do local. Essas trilhas foram criadas em 2001, com o auxílio da Secretaria Municipal de Turismo. Das trilhas criadas à época - Rosa Mochel, Baluarte, Hotel Fazenda e Joca Guimarães -, somente as duas últimas encontram-se em funcionamento.

\section{Metodologia}

O tipo de pesquisa utilizado para a consecução desta investigação foi a qualitativa que tem se mostrado bastante interessante em uma investigação científica para obtenção de dados a partir do contato do pesquisador com a situação objeto de estudo. A pesquisa qualitativa originou-se no campo das ciências sociais, com a utilização de métodos que pudessem descrever e explicar fenômenos em sua área de interesse. Este tipo de pesquisa envolve a obtenção de dados descritivos, no contato direto do pesquisador com a situação estudada.

O estudo proposto foi desenvolvido em duas etapas: a primeira correspondeu à pesquisa exploratória e descritiva que envolveu a busca de conhecimento através de pesquisas e revisões bibliográficas e documentais realizadas em literatura específica nas áreas de turismo, gestão ambiental e unidades de conservação por meio de consultas em livros, artigos científicos, sites da internet e em acervos documentais de instituições turísticas relacionados à temática abordada. A segunda correspondeu à pesquisa de campo para coleta de dados e informações sobre a área de estudo. Nesse sentido, foi utilizado o método da observação do tipo participativa a partir de visitas técnicas à área para averiguar a situação da APA da Região do Maracanã quanto a sua gestão.

\section{Elaboração do roteiro da entrevista}

Com o mesmo intuito, foram realizadas entrevistas, com perguntas semi-estruturadas, com agente ambiental que atua na APA e com representante da Secretaria de Estado de Meio Ambiente e Recursos Naturais do Maranhão. A entrevista como procedimento técnico de coleta de dados pode ser definida, de acordo com Schluter (2003, p. 106), como "um processo de interação entre duas pessoas na qual uma delas, o entrevistador, faz perguntas à outra", o entrevistado, com objetivo a obtenção de informações pertinentes ao tema estudado.

Ainda conforme observa (SCHLUTER, 2003, p. 107), a entrevista tem uma série de vantagens sobre os métodos de coleta de dados, pois: "permite obter dados relevantes e significativos para o estudo que está sendo realizado; permite obter uma maior quantidade de respostas". A realização das entrevistas nesta pesquisa objetivou levantar dados sobre a gestão da Área de Proteção Ambiental da Região do Maracanã. 


\section{Resultados}

Conforme já exposto, a gestão ambiental em unidades de conservação tem como propósito garantir a integridade dos seus recursos. Nesse sentido, deve eleger os instrumentos adequados à gestão da área que assegurem a minimização dos impactos negativos, garantam a participação de atores (poder púbico, iniciativa privada, comunidade, associações, dentre outros) no processo administrativo e sejam capazes de mediar conflitos na relação entre homem e os diversos recursos ali existentes.

A investigação realizada sobre a Área de Proteção Ambiental da Região do Maracanã, teve como propósito identificar qual(is) instrumentos é(são) utilizado(s) na gestão ambiental dessa área natural protegida e a forma de utilização destes.

De acordo com a pesquisa realizada no Cadastro Nacional de Unidade de Conservação (CNUC), - sistema integrado de banco de dados com informações sobre a administração das unidades de conservação, - o órgão gestor responsável pela APA da Região do Maracanã é a Secretaria de Estado de Meio Ambiente e Recursos Naturais do Maranhão (SEMA), por meio da Supervisão de Gestão das Unidades de Conservação, ligada à Superintendência de Biodiversidade e Áreas Protegidas. A APA foi criada em 1991, pelo Decreto 12.103/91, mas até hoje não possui um plano de manejo. Conforme dito anteriormente, este deve ser elaborado nos primeiros cinco anos de existência da unidade de conservação, pois se trata de instrumento de fundamental importância para a sua gestão. Ratificando o acima exposto, Barbieri (2007) ao tratar de gestão ambiental, observa que esta se refere ao planejamento, direção, controle, alocação de recursos e outras atividades necessárias ao alcance dos objetivos estabelecidos e a garantia da obtenção dos efeitos positivos sobre o meio ambiente. Nesse âmbito, o plano de manejo é decisivo para o alcance dos objetivos para os quais a UC foi criada. O Instituto Chico Mendes de Conservação da Biodiversidade (ICMBio, 2014) observa, ainda, que a elaboração do Plano de Manejo é determinante para a compreensão do conjunto de ações necessárias para a gestão da unidade de conservação e para garantir o uso sustentável dos recursos naturais durante as atividades desenvolvidas na área.

Em levantamento junto à SEMA, nos foi informado que o processo de discussão para a elaboração do plano de manejo da APA da Região do Maracanã foi iniciado. A Secretaria, por meio da Câmara Estadual de Compensação Ambiental (CECA), realizou reunião ordinária no dia 24 de julho de 2013 e a proposta de elaboração do Plano de Manejo constava na pauta dos trabalhos. Entretanto, de lá até então não houve avanço nas discussões.

No que se refere ao Conselho Gestor, a realidade apresentada não é diferente, ou seja, a Área de Proteção Ambiental da Região do Maracanã ainda não possui um Conselho Gestor. Conforme a SEMA, há uma mobilização para formação desse Conselho. Foram realizadas duas reuniões com representantes de organizações e sociedade civil que vivem ou atuam na área da APA do Maracanã para tratarem do assunto. Cabe lembrar que de acordo com o Decreto 4330/2002, o Conselho Gestor é 
constituído por representações de órgãos públicos e da sociedade civil, legalmente instituídos para a gestão da unidade de conservação visando sempre o alcance dos objetivos dessas áreas e dentre suas competências estão a compatibilização dos interesses dos distintos segmentos sociais aos da unidade.

A Supervisão de Gestão das Unidades de Conservação, ligada à Superintendência de Biodiversidade e Áreas Protegidas da SEMA, é responsável por administrar 13 unidades de conservação de âmbito estadual. Dentre suas principais responsabilidades estão:

Gerenciar as Unidades de Conservação sob jurisdição do
Estado [...]; manter atualizados dados referentes às
Unidades de Conservação existentes, fornecendo
informações para o diagnóstico ambiental, propondo
medidas de preservação ou conservação dos recursos
naturais e ambientais do Estado; aprovar, fiscalizar e
controlar o licenciamento de atividades, quando utilizados os
recursos naturais existentes nas UC; fomentar e
acompanhar a implantação dos planos de manejo das
Unidades de Conservação sob jurisdição do Estado; propor
mecanismos que garantam a participação da sociedade civil
no processo de criação e gestão das Unidades de
Conservação do Estado; propor, avaliar e acompanhar a
aplicação de recursos de compensação ambiental na gestão
das UCs Estaduais; emitir parecer técnico nos processos de
licenciamento ambiental de atividades potencialmente
poluidoras e degradadoras nas áreas de abrangência e do
entorno das Unidades de Conservação estaduais
(MARANHÃO, 2014).

O Sistema Estadual de Unidade de Conservação (SEUC, 2011), no artigo 45, determina que, para a instituição de conselhos gestores de unidades de conservação de uso sustentável, algumas normas devem ser observadas, conforme a seguir:

as Áreas de Proteção Ambiental, disporão de Conselhos Consultivos presididos pela chefia das mesmas ou representante do órgão executor do SEUC e constituídos por representantes dos órgãos públicos, de organizações da sociedade civil e dos povos e comunidades tradicionais residentes, quando for o caso.

Portanto, como apontou a pesquisa, não existe conselho gestor constituído, fato que compromete sobremaneira a manutenção dos recursos existentes na APA, pois, conforme exposto anteriormente, dentre as competências do conselho estão buscar estabelecer um equilíbrio entre os interesses dos distintos setores sociais ligados à unidade, bem como posicionar-se quanto às atividades que podem ser desenvolvidas no interior da área protegida a fim de evitar grandes impactos negativos à unidade de conservação. 
Quanto à visitação pública, cabe ressaltar que a APA da Região do Maracanã é conhecida pelas suas belezas naturais e culturais. No interior desta existem duas trilhas ecológicas comumente utilizadas para fins de visitação, oportunizando o contato com o patrimônio natural, histórico e cultural existente no local. De acordo com as Diretrizes para Visitação em Unidade de Conservação estabelecidas pelo Ministério do Meio Ambiente (2006),

a visitação consiste em um instrumento essencial para aproximar a sociedade da natureza e despertar a consciência da importância da conservação dos ambientes e processos naturais, independentemente da atividade que se está praticando na Unidade de Conservação.

bairro do Maracanã, onde está inserida a APA, é conhecido também pelo seu relevante patrimônio cultural. Anualmente, ocorre o Festival da Juçara ${ }^{1}$ que leva centenas de pessoas ao bairro para degustação do fruto no principal período de colheita. Outro grande atrativo, é o tradicional Bumba Meu Boi do Maracanã, um dos principais representantes do folclore maranhense. O conjunto de atrativos do bairro fez com que em 2014, a Associação Comunitária Maracanã Turismo (ACOMTUR), em parceria com uma agência de turismo local, criassem a "Rota do Açaí", um roteiro que inclui passeio por trilhas na floresta, visita ao barracão do Bumba Meu Boi do Maracanã, além da degustação de açaí, colhida pelos próprios visitantes. $O$ passeio dura cerca de 3 horas.

Como não existem dados sobre as atividades desenvolvidas na APA, não há como mensurar o número de visitantes, o impacto da visitação nas trilhas utilizadas e a integridade ambiental destas. Também não há informações quanto aos benefícios oriundos da visitação, ou seja, se um percentual dos recursos financeiros advindos da visitação é destinado à APA. As Diretrizes para Visitação em Unidade de Conservação (2006) asseveram que a visitação pública deve ser capaz de contribuir com 0 desenvolvimento econômico e social das comunidades locais envolvidas no processo.

A atividade de visitação em áreas protegidas pode ser um veículo eficaz quando o assunto é educação ambiental. Com base nesta afirmação, investigamos as ações direcionadas à Educação Ambiental dentro da APA e verificamos que, embora de maneira tímida, existem ações nesse âmbito. $O$ Centro Educacional Sagrados Corações (CESCO), instituição privada que fica localizada dentro da APA do Maracanã, é praticamente a única entidade que desenvolve, com alunos e docentes, ações e projetos voltados para a Educação Ambiental. Conforme a diretora da escola são realizadas oficinas e palestras sobre a conscientização ambiental e sustentabilidade que visam proporcionar aos alunos um aprendizado prático acerca das questões ambientais do lugar. $\mathrm{E}$ todas as disciplinas estão inseridas nos projetos desenvolvidos pela escola que são realizados sempre aos sábados. $O$ destaque é o "Projeto Amigos da Natureza", cuja proposta é desenvolver ações que contribuam com a conservação e a valorização do patrimônio natural e cultural da Região do Maracanã. Além desse, há também o "Projeto Limpeza de Rios", que consiste na limpeza das margens dos rios e 
de suas nascentes $s$ pelos alunos da escola e demais interessados da comunidade. Esses projetos são realizados com o apoio dos alunos da Universidade Estadual do Maranhão (UEMA) que possuem uma parceria com a escola. A escola oferece ensino do maternal ao $7^{\circ}$ ano do ensino fundamental II.

Contudo, cabe ressaltar que inexistem ações voltadas para a educação ambiental na APA durante a prática da atividade turística, mesmo considerando que essa atividade constitui elemento primordial para a interpretação da natureza e sensibilização dos visitantes no sentido de despertar nestes o interesse e o respeito pelo patrimônio natural e cultural da área protegida.

\section{Considerações finais}

A criação de Unidades de Conservação tem se apresentado como alternativa para conservar ou preservar o patrimônio ambiental existente no país. A gestão ambiental dessas áreas naturais protegidas, em geral perpassa pela ação institucional do poder público, cabendo a este, portanto, em suas diferentes esferas, garantir a salvaguarda desse patrimônio. A forma de gestão, bem como os instrumentos utilizados nesse processo, são decisivos para o êxito do cumprimento dos objetivos que levaram à criação da unidade de conservação.

No que tange à Área de Proteção Ambiental da Região do Maracanã, foram selecionados instrumentos de gestão para avaliar quais deles são utilizados em sua gestão, pois quando bem aplicados, esses instrumentos representam ferramentas fundamentais no processo de operacionalização da gestão ambiental, garantindo que a UC cumpra o papel para o qual foi criada.

Entretanto, a pesquisa apontou uma realidade de abandono vivenciada pela UC. Apesar de ter sido criada em 1991 até hoje não dispõe de um Conselho Gestor e de um Plano de Manejo, contrariando o que determina o SNUC. Assim, a unidade de conservação fica completamente vulnerável às ações antrópicas. Diante dessa realidade, fica claro que o desafio não é apenas criar unidades de conservação, mas sim, dotá-las de uma gestão adequada, a fim de que possam garantir a manutenção da diversidade biológica e dos recursos ambientais existentes em seus domínios.

No que concerne à Educação Ambiental, verificamos que apenas algumas ações são desenvolvidas na área, mas não são suficientes para garantir a sustentabilidade dessa unidade de conservação.

Por fim, cabe ressaltar que se nenhum dos instrumentos investigados está sendo aplicado na APA do Maracanã pelo simples fato de não existir gestão ambiental na UC. A vulnerabilidade a qual está submetida tende a se agravar se nenhuma providência for tomada, pois essa é uma área com níveis de ocupação cada vez maiores e diversificados, onde são encontradas áreas residenciais e comércios atacadistas e indústrias que começam a se instalar em suas proximidades. 


\section{Referências bibliográficas}

BARBIERI, J.C. Gestão ambiental empresarial: conceitos, modelos e instrumentos. São Paulo: Saraiva, 2007.

BITAR, O.Y.; ORTEGA, R.D. Gestão Ambiental. In: OLIVEIRA, A.M.S.; BRITO, S.N.A. (Eds). Geologia de Engenharia. São Paulo: Associação Brasileira de Geologia de Engenharia, 1998.

BORGES, T.M.C. Entrevista realizada dia 10 de junho de 2014 na escola Centro Educacional Sagrados Corações. São Luís, 2014.

BRASIL. Lei no 9.795, de 27 de abril de 1999. Dispõe sobre a educação ambiental, institui a Política Nacional de Educação Ambiental e dá outras providências. Brasília, $1999 . \quad$ Disponível em: $<$ http://www.planalto.gov.br/ccivil 03/leis/l9795.htm>. Acesso em: 15 jun. 2014.

BRASIL. Diretrizes para Visitação em Unidade de Conservação/Ministério do Meio Ambiente. Secretaria de Biodiversidade e Florestas. Diretoria de Áreas Protegidas. Brasília: Ministério do Meio Ambiente, (2006).

BRASIL. Lei no 9.985, de 18 de julho de 2000. Regulamenta o artigo $222 \S$ 1ํㅡ, incisos I, II, III, VII da Constituição Federal, institui o Sistema Nacional de Unidades de Conservação - SNUC. Diário Oficial da União, Brasília, DF, 19 jul. 2000a.

BRASIL. Ministério do Meio Ambiente. Convenção sobre diversidade biológica. Brasília: MMA, 2000b. (Série Biodiversidade, n. 1).

BRASIL. Decreto no 4.340, de 22 de agosto de 2002. Regulamenta artigos da Lei ำ 9.985, de 18 de julho de 2000, que dispõe sobre o Sistema Nacional de Unidades de Conservação da Natureza - SNUC, e dá outras providências. Brasília, 2002. Disponível em: <http://www.planalto.gov.br>. Acesso em: 10 jun. 2014.

BRASIL. Ministério do Meio Ambiente. Áreas Protegidas. Disponível em: $<$ http://www.mma.gov.br/areas-protegidas/unidades-deconservacao/conselhos-gestores $>$. Acesso em: 29 maio 2014a.

BRASIL. Ministério do Meio Ambiente. Cadastro Nacional de Unidades de Conservação. Disponível em: <http://www.mma.gov.br/areasprotegidas/cadastro-nacional-de-ucs>. Acesso em: 26 abr. 2014b.

BRITO, M.C.W. Unidades de Conservação: intenções e resultados. São Paulo: Annablume: FAPESP, 2000.

COSTA, P.C. Unidade de conservação: matéria-prima do ecoturismo. São Paulo: Aleph, 2002.

DENCKER, A.F.M. Pesquisa em turismo: planejamento, métodos e técnicas. São Paulo: Futura, 1998.

LEFF, E. Epistemologia ambiental. São Paulo: Cortez, 2001.

INSTITUTO CHICO MENDES DE CONSERVAÇÃO DA BIODIVERSIDADE.

Planos de Manejo. Disponível em:

$<$ http://www.icmbio.gov.br/portal/biodiversidade/unidades-de-

conservacao/planos-de-manejo.html>. Acesso em: 13 jun. 2014. 
MARANHÃO. Lei no 9.413, de 13 de julho de 2011. Institui o Sistema Estadual de Unidades de Conservação da Natureza do Maranhão - SEUC. São Luís, 2011.

MARANHÃO. Secretaria de Estado de Meio Ambiente e Recursos Naturais. Regimento Interno. Disponível em: <http://www.sema.ma.gov.br>. Acesso em: 14 jun. 2014.

SÃO PAULO. Governo do Estado. Secretaria do Meio Ambiente. Manual de Monitoramento e Gestão dos Impactos da Visitação em Unidades de Conservação. São Paulo: Secretaria de Meio Ambiente, 2010.

SCHLUTER, R. Metodologia da pesquisa em Turismo e Hotelaria. São Paulo: Aleph, 2003.

THEODORO, S.H.; CORDEIRO, P.M.F.; BEKE, Z. Gestão Ambiental: uma prática para mediar conflitos socioambientais. Centro de Desenvolvimento Sustentável/ Universidade de Brasília. Brasília, 2005.

Nota:

1 Nome dado ao açaí no Maranhão.

Rosélis de Jesus Barbosa Câmara: Universidade Federal do Maranhão, São Luís, MA, Brasil.

E-mail zelis.camara@yahoo.com.br

Link para o currículo Lattes: http://lattes.cnpq.br/1995690638678298

Rozuila Neves Lima: Universidade Federal do Maranhão, São Luís, MA, Brasil.

E-mail: rozuila@hotmail.com

Link para o currículo Lattes: http://lattes.cnpq.br/4654403359646517

Data de submissão: 28 de abril de 2015

Data de recebimento de correções: 29 de outubro de 2015

Data do aceite: 29 de outubro de 2015

Avaliado anonimamente 